\title{
USING GIS FOR TARGETING POVERTY: THE CASE OF GREAT CAIRO REGION
}

\author{
Ahmed O. El-Kholei and Ibrahim Sedky \\ Architectural Engineering Department, Faculty of Engineering, \\ Minoufiya University, Shebin El-Kom, Egypt
}

\begin{abstract}
The poverty mapping is a new technique that explores the relationship between spatial patterns of poverty and its geographic determinants. To achieve the goal of poverty reduction, the researchers collected, analyzed and used geographic information as it relates to the multi-dimensionality of poverty. Poverty maps are essential information used as an input to geographic targeting of deprivation, and thus formulating strategies for poverty reduction. Significant geographic variation in incidence rates of poverty may be due, in part, to differences in resource endowments, education, employment, infrastructures, health services, etc. As a consequence, inequity exists between districts as it does between individuals. This paper affirms the possibility of using geostatistical techniques for poverty mapping, and the suitability of GIS analysis for poverty targeting. At the district level, deprivation index for of Great Cairo Region as reported by HDR, 2006, and spatial variables that associate with poverty to generate digital layers of deprivation. The results spatially indicate deprived districts. Poverty maps of GCR are the results of spatial correlation analysis and geographic determinants of poverty.
\end{abstract}

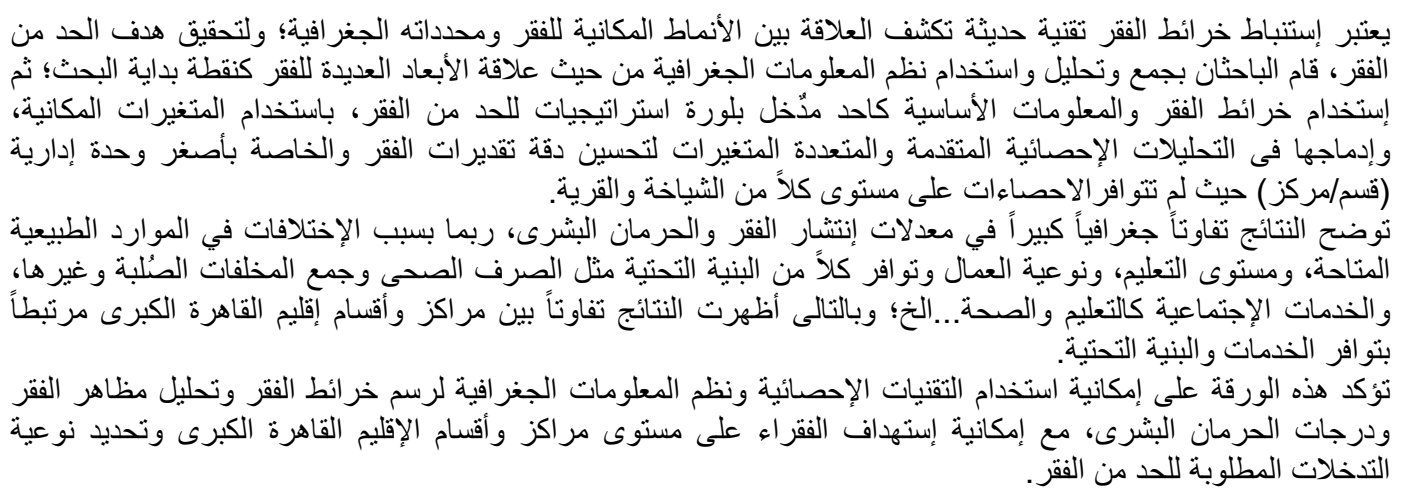

Keywords: Poverty, Greater Cairo Region, GIS, Poverty targeting.

\section{INTRODUCTION}

Poverty is a common attribute to many developing countries, and those in transition. Definitions of poverty are various depending on conceptual perspective, and the ultimate purpose for defining the poor. For some scholars, poverty associates with hunger and malnutrition, and thus they use per capita calories intake (often 2,400 kcal. a day) as their datum for defining the poor. Others use monetary standards to define the poor, such as those earning less than two US dollars a day. Another group of scholars define poverty as the inability to access wealth and resources, and opportunities as well.

Lacking a globally accepted definition of poverty, and who the poor are, is a hurdle to efforts for alleviating poverty. The question, also, is where are the poor is another challenge to the efforts for poverty alleviation. According to several studies evaluating the use of direct assistance, subsidies and other means for enabling the poor in many cases concluded these means are ineffective and inefficient as well. Targeting the poor is not an easy task, since the definitions of poverty are elusive and vague.

There are number of scholars that attempted to elaborate a more holistic measure of poverty. Moser (1998, 2004), for example, proposed six sets of indicators to comprehensively assess poverty and propose means for alleviating it. These sets are:

1. Percentage of urban poor, percentage of adults participating in the labor force and average hourly wage; 
2. The ratio of the price of a house to the income of the household, the ratio of rent to income household, tenure pattern;

3. Access to services and basic infrastructure, such as safe drinking water, sewerage, regular solid waste collection, and electricity;

4. The ability to afford urban and social services, for example, the portion of household income spent on education or health;

5. The ratio of government spending on infrastructure as an indirect measure of the supply of infrastructure for residential development; and finally,

6. gender-specific indicators, such as the number of female-headed households living under the poverty line.

Recently, number of scholars developed poverty maps to target the poor, and thus address their needs. The World Bank encourages and supports the use of geographical targeting for poverty alleviation. Examples include Mistiaen et. al (2002),"Putting Welfare on the Map in Madagascar" [1]. Poverty maps visually summarize complicated economic and social information in a map, thus supporting the processes of decision-making. The World Bank has set up a site that describes information sources, tools, and types of maps, including small area estimation maps, which involves imputing into population census data a measure of per capita consumption from household survey data. However, lacking disaggregate-level data on household resources often restricts the efficient use of these poverty maps.

Egypt is not different. There has been an extensive literature on measuring poverty. Researchers explored alternative welfare indicators because of lacking direct information on household resources at a finely disaggregated level. They look into available data at the local level on variables that associate with local poverty conditions. There, however, has always been a dispute on whether those proxies provide a fair picture of the household living standard. Alternatively, some researchers focused on producing estimates of income poverty for few aggregate levels within Egypt, such as a governorateor region-level due, in part, to the above mentioned problem of data limitation. To the best of our knowledge, none of the previous researchers used small-area estimation technique to produce locallevel poverty estimates for all localities in Egypt.

The paper addresses three interrelated sets of research questions: First, what are the poverty population locations? What are the criteria for evaluation? Answering this question is important for clarifying objectives, which may be multiple, e.g., direct income poverty reduction, improvement of non-income dimensions, improvement of key determinants, etc. Second, why develop a poverty maps? How well are target groups identified and reached? Third is how to identify the urban poor? What are characteristics of urban poverty? How to mapping poverty gaps?

The paper aims to address how to identify the most physically deprived areas in a metropolis and its region. The current study uses information available on the most basic GIS layers to produce layers reflecting various sorts of physical deprivation using basic administrative units. These maps provide policy makers with a tool that enables zooming on the most deprived zones that are most likely to be obscured as a result of relying on aggregate data on the level of the Governorate.

The significance of this paper is attempting to combine deprivation factors, as means to estimate poverty indicators and draw poverty maps. It attempts to show how statistics and Geographic Information Systems (GIS) help in mapping poverty and decision making to alleviate poverty.

\section{RESEARCH METHODOLOGY}

\subsection{Who are the Poor? Where are they?}

Applying quantitative poverty measures to a city is the start of a city profile distinguishing the poor from middle- and upper income households, as well as estimating the relative sizes of these groups; identifying their characteristics; facilitating the process of identifying the location of the poor, and highlighting groups that may be particularly vulnerable to poverty, such as female-headed households, migrants, youth, etc. This basic data can be used to select more in-depth qualitative measures.

A city poverty profile is a spatial tool, defining the extent and nature of poverty within a given area. It provides an accurate mapping of where the poor lives. It is an important input required for targeting appropriate responses. Spatial information on land use patterns, slum location, and location of facilities using Geographic Information Systems (GIS) are also critical inputs. In many cases, especially when the poor live in informal settlements, they may not be included in existing administrative data.

\subsection{Approaches to Measuring Urban Poverty}

Poverty is multidimensional [2] thus measuring it presents a number of challenges. Money-metric methods are widely used because they are objective measures used as the basis for a range of socioeconomic variables, and it is possible to adjust for differences between households, and intra household inequalities.

Despite these advantages, money-metric poverty measures have some shortcomings. Survey designs 
vary significantly between countries and over time, making comparability difficult. Some use income based measures, other consumption. Decisions about how to value housing, homegrown food and how to account for household size and composition all affect poverty estimates. If not properly adjusted, monetary measures can underestimate urban poverty because they do not make allowance for the extra cost of urban living (housing, transport, and lack of opportunity to grow one's own food) [3].

Income or consumption measures also do not capture many of the dimensions of poverty. For example, in the urban context, the urban poor rely heavily on the cash economy thus making them more vulnerable to fluctuations in income, as well as severe environmental and health hazards due, in part, to crowded living conditions in urban slums, and lacking tenure security. Other aspects of poverty relate to access to infrastructures and social services, such as water, sewage, health and education, and a safety net to mitigate hard times [4].

Number of approaches summarized below measure poverty. Regardless of the methodology chosen, the data should ideally be comparable across units of analysis, such as cities; and allow for disaggregation at the sub-unit of analysis level, such as the intra-city level, to capture differences between the poor in urban slums and informal areas within a metropolitan area.

The first methodology to measuring poverty is income and/or consumption measures: Both are based on data that assess whether an individual or household can afford a basic basket of goods (typically food, housing water, clothing, transport, etc.). Consumption is generally considered to be a better measure than income because incomes tend to fluctuate over time; there are problems of underreporting (particularly income derived from the private and informal sectors) [5]. Money metric measures can be adjusted to account for the higher cost of living in urban areas when measuring poverty.

The second measure is to construct Unsatisfied Basic Needs Index (UBNI). This approach defines a minimum threshold for several attributes of poverty classifying those households who do not have access to these basic needs. These attributes include literacy, school attendance, piped water, sewage, adequate housing, overcrowding, and some kind of caloric and protein requirement. If a household lacks one of these attributes, then the household is poor and does not meet its basic needs [6].

The third approach for measuring poverty is developing and inventory of asset indicators. This approach has been increasingly used with the Demographic and Health Surveys (DHS).
Researchers use a range of variables on the ownership of household assets to construct an indicator of households' socio-economic status. These assets include: a car, refrigerator, television, dwelling characteristics, such as type of roof, flooring, availability of a toilet; and access to basic services including clean water and electricity [7].

Assessment of vulnerability is the fourth measure of poverty. Vulnerability is the probability of being exposed to a number of risks, such as violence, crime, natural disasters, dropping out of school, etc. Indicators that measure vulnerability include, but are not limited to, physical assets, human capital, income diversification, links to networks, participation in formal safety nets, access to credit markets and so forth. This kind of analysis can be quite complex. It requires a specially designed survey [8].

Last but not least is the use of participatory methods that relies on tools of qualitative inquiry to capture aspects of urban poverty that may not be identified through pre-coded surveys. These tools are various including focus group discussions, case studies, and individual open-ended interviews and the like. Through these techniques, it is possible to determine the perceptions of poverty, identify priority needs and concerns, and gain insight on the effectiveness of programs from the beneficiaries' view.

To conclude this discussion, there is a need to reexamine poverty. It is not a static concept. It incorporates a number of components, such as risk, vulnerability and insecurity. Slums are not hotbeds of revolution; but rather absorb and integrate upwardly moving migrants and city-born urban citizens. Housing is the most important intergenerational asset of the poor and valorizes through, incremental infill, house upgrading, and plot densification. It is crucial to emphasize to disjuncture aspiration and opportunities for migrants in urban areas [9]. Table 1 presents urban poverty measurement implications.

\section{POVERTY IN EGYPT}

The 2006 Egypt Poverty Report indicated that an estimated 19.6 percent of Egyptians were poor, of which 3.8 percent were ultra-poor. In other words, about 13.6 million Egyptians (one out of every five) had consumption expenditure below the poverty line, and therefore could not satisfy their basic food and non-food needs. An estimated 2.6 million poor Egyptians could not satisfy their basic food requirements even if they had to spend all their income on food. In addition, there were 14.6 million Egyptians (or 21 percent of the population) who were near poor as Fig. 1 renders. 
Table 1, Understanding different dimensions of poverty: Asset Ownership and Vulnerability

\begin{tabular}{|c|c|}
\hline Dimension & $\begin{array}{l}\text { Distinctive aspects of poverty in } \\
\text { cities }\end{array}$ \\
\hline Income poverty & $\begin{array}{l}\text { Dependence on cash for purchases } \\
\text { of essential goods and services }\end{array}$ \\
\hline \multirow[t]{5}{*}{$\begin{array}{l}\text { Education and } \\
\text { health poverty }\end{array}$} & $\begin{array}{l}\text { Residential environments are prone } \\
\text { to industrial and traffic pollution } \\
\text { due, in part, to juxtaposing } \\
\text { residential and industrial functions } \\
\text { in cities }\end{array}$ \\
\hline & $\begin{array}{l}\text { Injury and deaths rising from traffic } \\
\text { Industrial occupational risks }\end{array}$ \\
\hline & $\begin{array}{l}\text { Working conditions, especially for } \\
\text { those in informal-sector jobs }\end{array}$ \\
\hline & $\begin{array}{l}\text { Constrained access to education due } \\
\text { to insufficient school sizes in } \\
\text { rapidly growing cities } \\
\text { Inability to afford school expenses }\end{array}$ \\
\hline & $\begin{array}{lrr}\begin{array}{l}\text { Personal safety/security } \\
\text { deterring school attendance }\end{array} & \text { risks } \\
\end{array}$ \\
\hline $\begin{array}{l}\text { Tenure } \\
\text { insecurity }\end{array}$ & $\begin{array}{l}\text { Land and housing in authorized } \\
\text { areas are not affordable, so the poor } \\
\text { occupy land illegally and construct } \\
\text { their houses without construction } \\
\text { and occupancy permits }\end{array}$ \\
\hline $\begin{array}{l}\text { Financial } \\
\text { insecurity }\end{array}$ & $\begin{array}{l}\text { Drug/alcohol abuse and domestic } \\
\text { violence; family breakdown and } \\
\text { reduced support for children; social } \\
\text { diversity }\end{array}$ \\
\hline $\begin{array}{l}\text { Social and } \\
\text { political }\end{array}$ & $\begin{array}{l}\text { Illegitimacy of residence and work } \\
\text { Isolation of communities that are } \\
\text { disconnected from jobs and services } \\
\text { Insufficient channels to obtain } \\
\text { information, for instance about jobs } \\
\text { or legal rights }\end{array}$ \\
\hline
\end{tabular}

Source: Moser, C., M. Gatehouse, and H. Garcia. 1999b. "Urban Poverty Research Sourcebook Module II: Sub-City Level Household Survey." Urban Management Program Working Paper Series No. 5. UNDP/UNCHS (HABITAT)/World Bank, Washington, D.C.

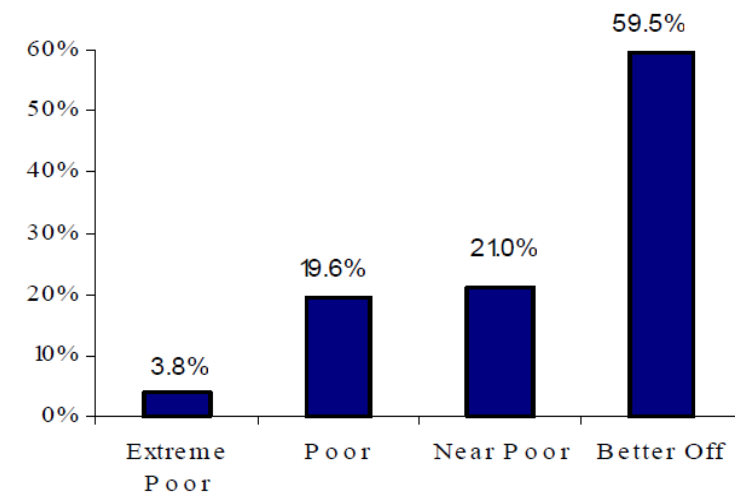

Fig. 1 Distribution of the Population of Egypt, 2005

Source: Al-Shawarby, Sherine, Arab Republic of Egypt: Poverty Assessment Update, 2006, Ministry of Economic Development and World Bank Cairo, Egypt

http://www.mop.gov.eg/pdf/povert_report.pdf accessed 20 April 2010.
Poverty is evident in Upper Egypt. Poverty associates with rural areas; and districts with least poverty incidents are those metropolitan. While governorates of Upper Egypt generally had a high incidence of poverty, the Governorate of Giza had relatively low poverty rates (12 to 13 percent) compared to Governorates of Lower Egypt, such as Sharqia, Behira, and Menofia with poverty incidence of 17 to 28 percent, Fig. 2. The Governorate of Cairo has the least concentration of poor population; unlike Asyut that has the highest percentage of poor population, which is about 60 percent.

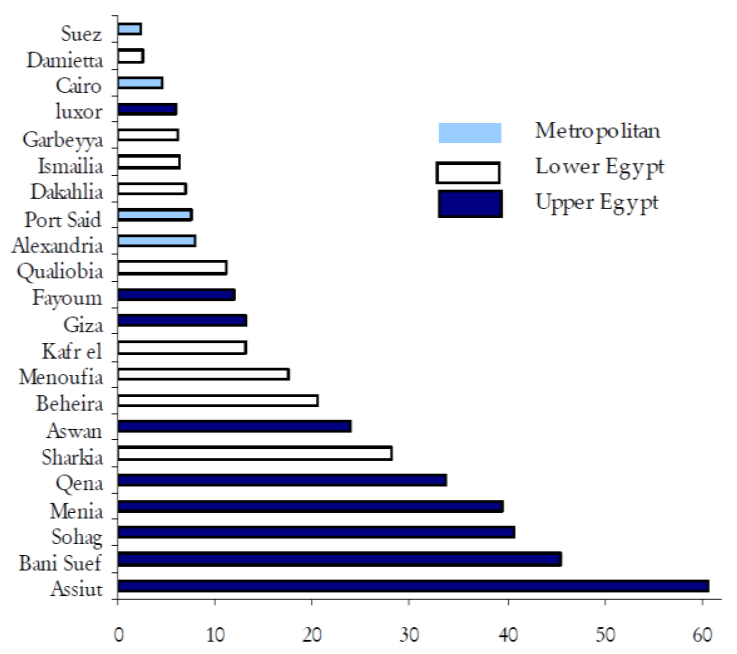

Fig. 2 Poverty Incidence by Governorate

Source: Al-Shawarby, Sherine, Arab Republic of Egypt: Poverty Assessment Update, 2006, Ministry of Economic Development and World Bank Cairo, Egypt

http://www.mop.gov.eg/PDF/povert_report.pdf accessed 20 April 2010.

According to the report, there are major variations in poverty rate. It ranged from 65 percent in Qusya City, Asyut, where about 70 thousands persons live, to 0.4 percent in Eastern Abbasiya in Cairo.

Larger households are at a higher risk of poverty. In 2005, almost half of all Egyptian households were five or more persons. Households consisting of one or two persons had considerably lower poverty rates than larger households that year. Almost one third of all households with six or more persons are poor, accounting for 74 percent of Egyptian poor, Fig. 3 .

The report affirms that children and youth experienced poverty. At the national level, in 2005, 21 percent of young children, those less than 15 years old, lived in poverty.

Education is one the key determinants of poverty, Fig.s 4 and 5. Whether they live in urban or rural area, illiterates, those with basic education and those holding university degrees are poor. Illiterate persons and those with basic education are confined to manual, unskilled labor; while university graduates 
lack skills necessary to compete for job opportunities. Only those skilled technical labors fall on the border line of poverty, and run the risk of slipping under the poverty line in case of economic or environmental crisis. There is a spatial explanation of the both education and availability of jobs opportunity. Rural areas, particularly Upper Egypt, lack educational services, and are in need for investments to generate job opportunities. It is wellknown fact that most migrants to Cairo and Alexandria, and to other oil producing countries, and illegal migration to the Europe come from the Governorates of Upper Egypt.

\section{EMPIRICAL VERIFICATIONS}

\subsection{Data Sources}

Using results of 2006 census and available information for HDR, the researchers constructed an Area-based Physical Deprivation Index using discriminant analysis. "Discriminant analysis techniques are used to classify individuals into one of two or more alternative groups" [10] It is used to identify which variables contribute to making the classification. The linear combinations of variables are used to distinguish between the groups [11].

The Greater Cairo Region is the case study to empirically verify the validity of using GIS analyses to determine poverty pockets. Between 1947 and 2006, the population of the region grew from 1.5 million inhabitants to more than 18 million inhabitants. According to the results of the 2006 census, the population of GCR represents about 20 percent of the total population of Egypt; and 36 percent of the urban population in Egypt; Table 2 shows the population of the five Governorates of GCR.

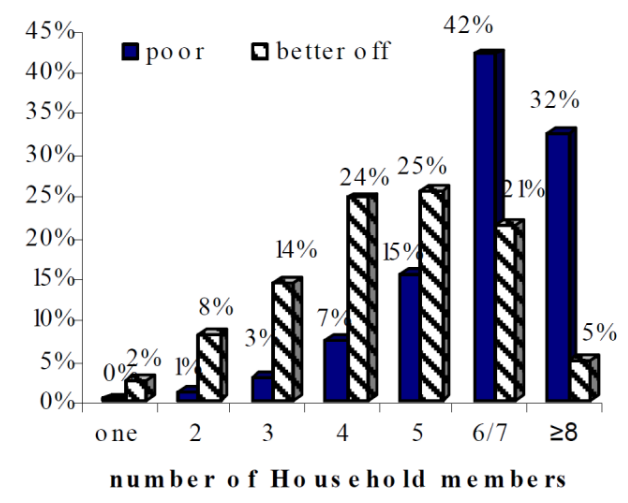

Fig. 3 Number of household members

Source: Al-Shawarby, Sherine, Arab Republic of Egypt: Poverty Assessment Update, 2006, Ministry of Economic Development and World Bank Cairo, Egypt.

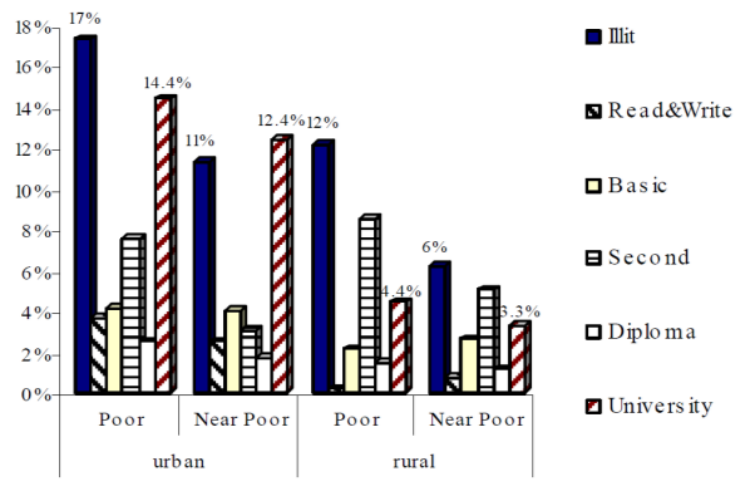

Fig. 4 Educational and poverty, 2005

Source: Al-Shawarby, Sherine, Arab Republic of Egypt: Poverty Assessment Update, 2006, Ministry of Economic Development and World Bank Cairo, Egypt

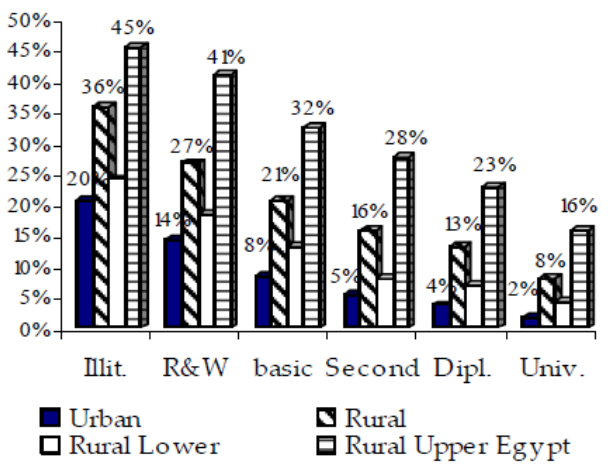

Fig. 5 Poverty Incidences stratified by education level of the head of household, 2005

Source: Al-Shawarby, Sherine, Arab Republic of Egypt: Poverty Assessment Update, 2006, Ministry of Economic Development and World Bank Cairo, Egypt.

Table 2, Population of Greater Cairo Region, 2006

\begin{tabular}{|c|c|c|c|}
\hline Governorates & Urban & Rural & Total \\
\hline Cairo & $6,758,581$ & 0 & $6,758,581$ \\
\hline Giza & $2,891,275$ & 252,211 & $3,143,486$ \\
\hline Qalyubia & $1,899,354$ & $2,352,318$ & $4,251,672$ \\
\hline Helwan & $1,202,395$ & 510,833 & $1,713,278$ \\
\hline 6th October & 745,875 & $1,835,184$ & $2,581,059$ \\
\hline Total & $13,497,480$ & $4,950,546$ & $18,448,076$ \\
\hline
\end{tabular}

The total inhabited area of GCR is about $190 \mathrm{~km}^{2}$. Thus the gross population density is around 41 thousand inhabitants per square kilometer. Informal areas, including slums, squatter settlements, and informal developments on agricultural land is a major characteristic of GCR, Fig. 6. 


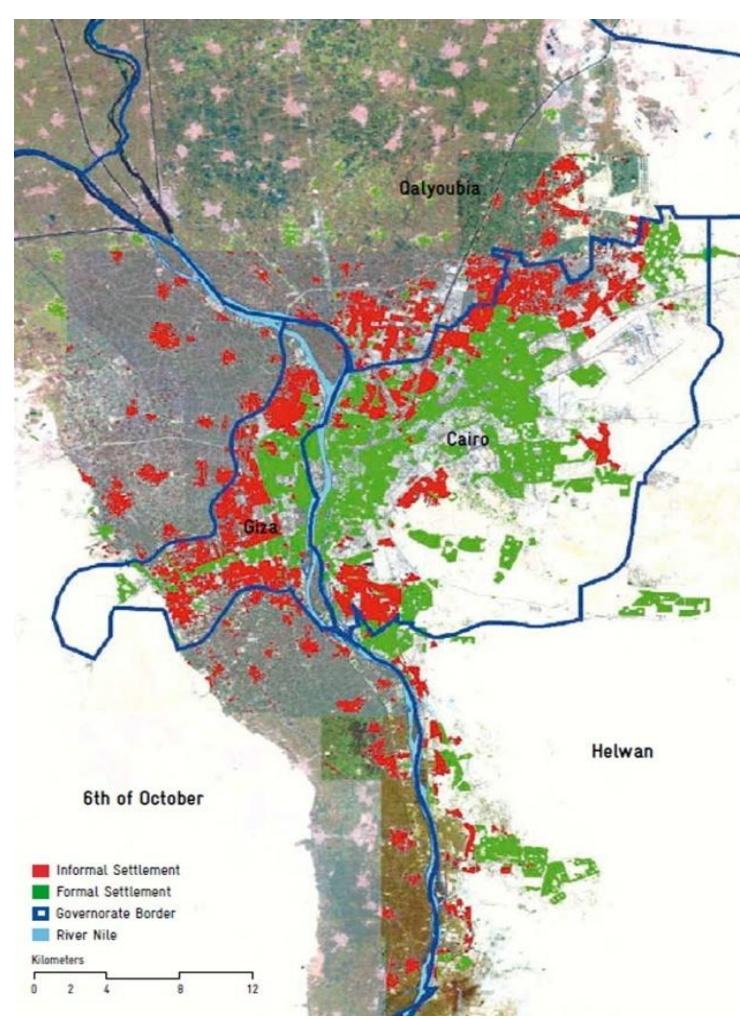

Fig. 6 Formal and informal areas within the Greater Cairo Region

Source GTZ, Cairo's Informal Areas: Between Urban Challenges and Hidden Potentials, Facts, Voices, Visions, Cairo, Egypt, 2006, Page 28 .

Administratively, GCR consists of 79 qism and markaz [12]. To certain extent, these divisions are equivalent to socially-identified, homogeneous communities. For this reason, these administratively defined communities are the units of analysis in this study.

Most of the studies tell little on poverty in GCR since often poverty analyses are either at the national level; or use governorates as their units of analysis. Poverty reports usually classify governorates into urban, rural, and Upper Egypt and Lower Egypt. They also use Household Consumption Survey. The attempt to examine individual community using macro- or meso-level data can easily lead to ecological fallacies. Economic and environmental limits do not usually abide by administrative boundaries, and for this reason examining the spatial distribution of poverty and deprivation is not totally proper using administrative boundaries of Governorates.

\subsection{Defining Variables}

Most urban poverty studies will target only a particular aspect of urban poverty. For this reason, the researchers attempted to construct an Area-based Physical Deprivation Index (APDI). It results from information analyzed to produce two different groups of GIS layers for GCR. The first group of layers is layers of surface objects. It includes, roads, the Nile, administrative layers that show the administrative boundaries of each administrative unit of analysis, whether qism or markaz, in Cairo, Giza, $6^{\text {th }}$ of October, Qalyubia and Helwan. This step was to include both urban and rural areas of GCR in the analysis. The second group of layers is about data collected from 2006 census, and results of statistical analyses.

\subsection{Method}

Indices and variables demarcating poverty pockets in GCR are the result of over laying the all dominant layers of maps (roads and administrative boundaries and discriminate results) for each qism/markaz. Three indices measure social differentiation in GCR. First is population stratified by employment; second is population classified by educational status; and third, population grouped by deprivation index.

GIS techniques might be the perfect tools to identifying causes of poverty, but are less successful in providing a full assessment of the effect of poverty. GIS can show that a lack of environmental amenities such as access to markets (roads) and social services, such as education, can explain the spatial location of poverty within a metropolis.

First, the researchers conducted correlation analysis to investigate associations of the characteristics the common deprived population, and examine the interrelationships among a set of variables [13]. Next, the researchers used discriminant analysis to estimate discriminant functions, and then saved scores to derive GCR poverty maps.

\subsection{Analysis and Results}

\subsubsection{Correlation analysis}

Correlation analysis is used to investigate the common characteristics of different qism, the analysis examine the interrelationships among a set of variables. It identifies mathematical vectors accounting for the variance common to several variables which are inter-correlated [14].

Table 3, shows an inverse association between deprivation index and real per capita GDP, and formality, which has an inverse relationship with educational status. The strong correlation between illiteracy and ability to read and write sheds doubts in efforts of eradicating illiteracy. It suggests the likelihood of slipping back to illiteracy. 
Table 3, Correlation Matrix 1

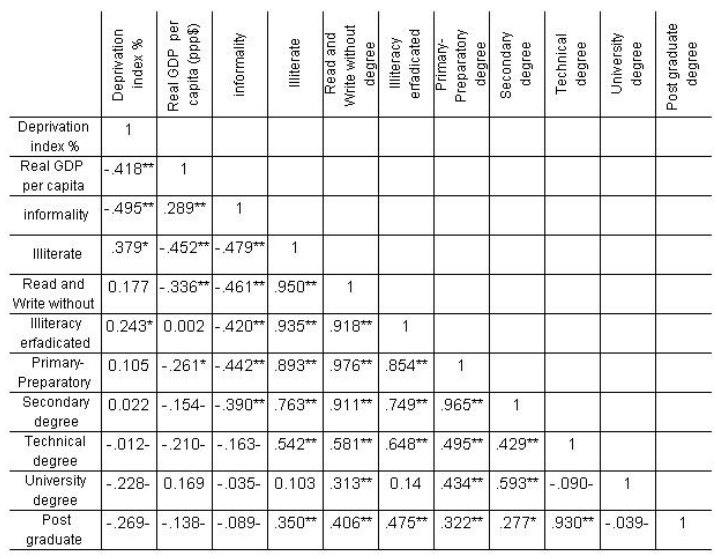

Table 4 presents relationship between deprivation index and housewives, who are employed without wage within the family. They are correlated to business owners. Unemployed persons and students are positively correlated with those working for wage.

Table 4, Correlation matrix 2

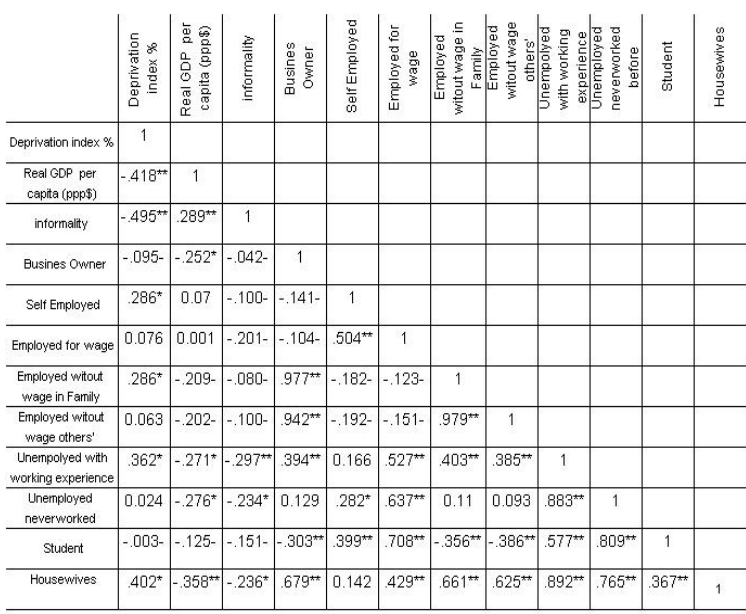

To conclude, employment status and educational level together with informality are major determinants of deprivation and per capita share of GDP. The question where these attributes prevail can only be answered by a statistical technique for grouping and then GIS to map poverty.

\subsubsection{Discriminant analysis}

The first step to conduct a discriminant analysis was to decide on the groups. The researchers decided on classifying the districts of GCR into three distinct groups: urban-formal, urban-informal, and rural. The urban informal are slum areas within downtown and old quarters; squatter settlements on the hinterlands of the metropolis, and invasion developments on valuable agricultural land, such as that around the Ring Road, for example.

\section{Grouping according to educational status}

By carrying out discriminant analysis using deprivation index as the dependent variable, and variables that measure educational status as independent variable. Table 5 presents Eigen values, variances of groups. Find function 1 Eigen value .811 and Wilks' Lambda [15], 1 through 2 equal 0.469 , because the two groups are not equal in number of observations and the sample is highly heterogeneous the probabilities were calculated based on size. It means that education status can explain location of deprivations. The first function explains 82.2 percent of the variation in the deprivation index. According to the results of that run, 76.7 percent of the cases were correctly grouped.

Table 5, Summary of canonical discriminant using educational status

\begin{tabular}{cccccc}
\hline \multicolumn{6}{c}{ Eigen values } \\
\hline Function & $\begin{array}{c}\text { Eigen } \\
\text { value }\end{array}$ & $\begin{array}{c}\text { \% of } \\
\text { Variance }\end{array}$ & Cumulative \% & $\begin{array}{c}\text { Canonical } \\
\text { Correlation }\end{array}$ \\
\hline 1 & $0.811 \mathrm{a}$ & 82.2 & 82.2 & & 0.669 \\
2 & $0.176 \mathrm{a}$ & 17.8 & 100.0 & 0.387 \\
\hline Wilks' Lambda & & & \\
\hline \multicolumn{7}{c}{ Test of } & Wilks' & Chi-square & df & Sig. \\
Function(s) & Lambda & & & \\
\hline 1 through 2 & 0.469 & 54.821 & 16 & 0.000 \\
2 & 0.850 & 11.752 & 7 & 0.109 \\
\hline
\end{tabular}

Table 6 presents standardized canonical discriminant function coefficients. It shows that variables measuring illiteracy, ability to read and write, and preparatory education all identify deprived location in GCR. Technical and university degree have inverse relationship. Post graduate degree has a positive relation. This means those with technical education have a better chance to escape deprivation, unlike those with graduate and post-graduate degrees. There are number of reasons. The quality of the graduate might not be suitable to jobs on the market in Egypt; others might leave the country for better, relevant job opportunity abroad, which manifest itself in the form of brain drain.

Table 6, Standardized Canonical Discriminant Function Coefficients

\begin{tabular}{lcc}
\hline Variables & \multicolumn{2}{c}{ Function } \\
\cline { 2 - 3 } & 1 & 2 \\
\hline Illiterate & 0.645 & 0.214 \\
Read and Write without degree & 0.693 & $-1.451-$ \\
Illiteracy eradicated & $-0.292-$ & 1.977 \\
Primary-Preparatory degree & $0.682-$ & $-1.623-$ \\
Secondary degree & 1.488 & 1.259 \\
Technical degree & $-2.040-$ & 0.961 \\
University degree & $-0.891-$ & $-0.096-$ \\
Post graduate degree & 1.504 & $-0.800-$ \\
\hline
\end{tabular}


The Structure matrix shows that Read and write without degree, illiterate, primary-preparatory degree, secondary degree, and illiteracy eradicated are the significant variables of function 1 which explains 82.2 percent of the variation of the deprivation index. Function 2, which consists of technical degree, graduate and post-graduate degrees, explains the remaining 17.8 percent.

Table 7, Structure matrix

\begin{tabular}{lrr}
\hline Variables & \multicolumn{2}{c}{ Function } \\
\cline { 2 - 3 } & \multicolumn{1}{c}{1} & \multicolumn{1}{c}{2} \\
\hline Read and Write without & $0.817^{*}$ & 0.254 \\
degree & & \\
Illiterate & $0.812^{*}$ & 0.383 \\
Primary-Preparatory degree & $0.788^{*}$ & 0.125 \\
Secondary degree & $0.685^{*}$ & 0.031 \\
Illiteracy eradicated & $0.670^{*}$ & 0.622 \\
Technical degree & 0.246 & $0.470^{*}$ \\
Post graduate degree & 0.151 & $0.323^{*}$ \\
University degree & 0.116 & $-0.302^{*}$ \\
\hline
\end{tabular}

Districts with high discriminant scores are presented in dark tones. These are area with high concentration of illiterate or eradicated illiteracy, basic and secondary education. These districts (qism/markaz) include El-Basateen, Imbaba, Boulaq El Dakrour, El-Marg, Badrashein, Ayat Markaz, Banha Qism, Al Omraniya, El-Salaam, El-Matariya, $15^{\text {th }}$ of May, Shebin El-Qanater, Shubra El-Khaima $1^{\text {st }}$, Imbaba Markaz, Shubra El-Khaima $2^{\text {nd }}$, Manchiet Nasser, al-Waraq, Oseem Markaz, Ain Shams and Khanka. Districts with extremely light tones are those with the least concentration of those individuals with inferior education, and of course have the least scores of depravation and poverty. Zamalek, Nasr City, Ma'adi, Heliopolis, $6^{\text {th }}$ of October, New Cairo are among examples of the districts with the least deprivation. Districts with medium tone are those with medium discriminant scores, and also population of medium educational status, probably technical education. District of that category include most of the districts of the Governorate of Qalyubia and parts of the Governorate of Helwan belong to this group.

\section{Grouping according to employment status}

Deprivation also associates with employment status, as resulted from the correlation matrices. Table 8 presents Eigen values, variances of groups. Find function 1 Eigen value. 0.644; and Wilks' Lambda 1 through 2 equal 0.203. Employment status can identify locations of deprivations. Function 1 has a considerable low Wilks' Lambda, and explains about 63 percent of the variation in the deprivation index.

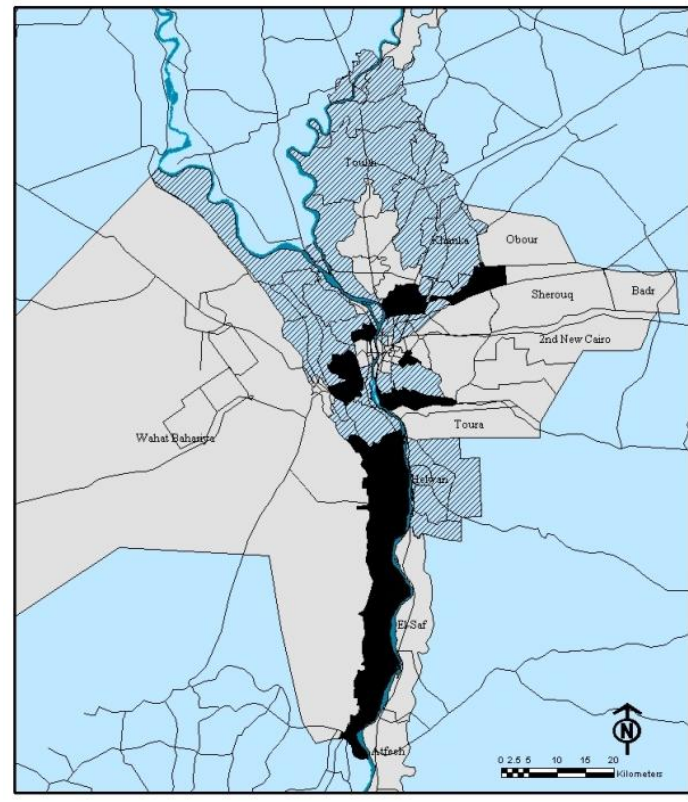

Fig.7 Scores of education discriminant analysis

Table 8, Employment summary of canonical discriminant

\begin{tabular}{|c|c|c|c|c|}
\hline \multicolumn{5}{|c|}{ Eigen values } \\
\hline Function & $\begin{array}{l}\text { Eigen } \\
\text { value }\end{array}$ & \multicolumn{3}{|c|}{$\begin{array}{c}\% \text { of Variance Cumulative Canonical } \\
\% \quad \text { Correlation }\end{array}$} \\
\hline 1 & $.644 a$ & 62.9 & 62.9 & 0.443 \\
\hline 2 & $.144 a$ & 37.1 & 100 & 0.354 \\
\hline \multicolumn{5}{|c|}{ Wilks' Lambda } \\
\hline \multicolumn{2}{|c|}{$\begin{array}{c}\text { Test of } \\
\text { Functions }\end{array}$} & $\begin{array}{l}\text { Wilks' } \\
\text { Lambda }\end{array}$ & $\begin{array}{l}\text { Chi- } \\
\text { square }\end{array}$ & Sig. \\
\hline \multicolumn{2}{|c|}{1 through 2} & 0.203 & 25.386 & 0.115 \\
\hline \multicolumn{2}{|l|}{2} & 0.874 & 9.668 & 0.289 \\
\hline
\end{tabular}

Table 9 presents standardized canonical discriminant function coefficients. The first discriminant function derived from employment data suggests that unemployed with working experience, employed for wage, employed without wage in family business, employed for wage and housewives are major discriminating variables. An estimated 83.7 percent of the cases were properly grouped to enter the analysis, explaining 62.9 percent of the variation in the deprivation index. Function 1 is about those who do not own their business, employed for wage or without wage for the family, and those unemployed a characteristic of the poor. The table does not show much difference between Function 1 and 2. Function 2, which explains 37.1 percent of the variation in depravation index, is also loaded with those unemployed, without their own business as indicated by the negative sign of the canonical discriminant function coefficient. 
Table 9, Standardized canonical discriminant function coefficients

\begin{tabular}{lrc}
\hline Variables & \multicolumn{2}{c}{ Function } \\
\cline { 2 - 3 } & \multicolumn{1}{c}{1} & 2 \\
\hline Business Owner & $-.884^{*}$ & $-.593^{*}$ \\
Self Employed & 0.296 & $-.244^{*}$ \\
Employed for wage & 0.556 & $-.433^{*}$ \\
$\begin{array}{l}\text { Employed without wage in } \\
\text { Family business }\end{array}$ & 0.527 & $-3.746^{*}$ \\
$\begin{array}{l}\text { Employed without wage } \\
\text { others' business }\end{array}$ & 0.250 & 3.776 \\
$\begin{array}{l}\text { Unemployed with working } \\
\text { experience }\end{array}$ & 0.958 & $-.345^{*}$ \\
$\begin{array}{l}\text { Unemployed never worked } \\
\text { before }\end{array}$ & 0.275 & $-1.994^{*}$ \\
$\begin{array}{l}\text { Student } \\
\text { Housewives }\end{array}$ & $-.642-$ & 1.019 \\
\hline
\end{tabular}

The structure matrix, Table 10, shows that unemployed with working experience; employed for wage; unemployed never worked before; housewives; student; and self employed are major variables of function 1 . These variables are strong attributes of the poor.

Table 10, Structure matrix

\begin{tabular}{lll}
\hline Variables & \multicolumn{2}{c}{ Function } \\
\cline { 2 - 3 } & 1 & 2 \\
\hline $\begin{array}{l}\text { Unemployed with working } \\
\text { experience }\end{array}$ & $.794^{*}$ & 0.219 \\
$\begin{array}{l}\text { Employed for wage } \\
\quad \text { Unemployed never worked }\end{array}$ & $.722^{*}$ & $-.250-$ \\
before & $.704^{*}$ & $-.006-$ \\
Housewives & & \\
Student & $.639^{*}$ & 0.389 \\
Self Employed & $.466^{*}$ & $-.231-$ \\
$\begin{array}{l}\text { Employed without wage } \\
\text { others' business }\end{array}$ & $.431^{*}$ & $-.270-$ \\
$\begin{array}{l}\text { Retired } \\
\text { Employed without wage in }\end{array}$ & 0.204 & $.586^{*}$ \\
Family business & 0.195 & $.520^{*}$ \\
Business Owner & 0.191 & $.484^{*}$ \\
\end{tabular}

Using discriminant scores of function 1 to map poverty resulting from employment status elaborated Fig. 8. Areas with high discriminant scores shaded in dark color, such as Imbaba, Shubra El-Khaima 1, ElSalaam, Shubra El-Khaima 2, El-Matariya, Ain Shams, Boulaq El Dakrour, $15^{\text {th }}$ of May, Agouza, ElZawia El Hamra, Sheikh Zayed, Badr, Banha Qism, El-Bassateen, Giza Markaz, Doqqi, Madinat Nasr 1, El-Zaytoun, Hadaok El Quba, El-Khousous, are areas of high deprivation as a result of inadequate employment status. Districts in lighter colors, such as Zamalek, Nasr City, Heliopolis, Helwan, are areas with the opposite employment status. The majority is white collar jobs such as those self employed, own their businesses, members of the upper echelon of government positions and the like. Areas with medium tone are those with medium scores representing a mix of employment status, such as Shubra, Qasr El Nil, $6^{\text {th }}$ of October, etc.

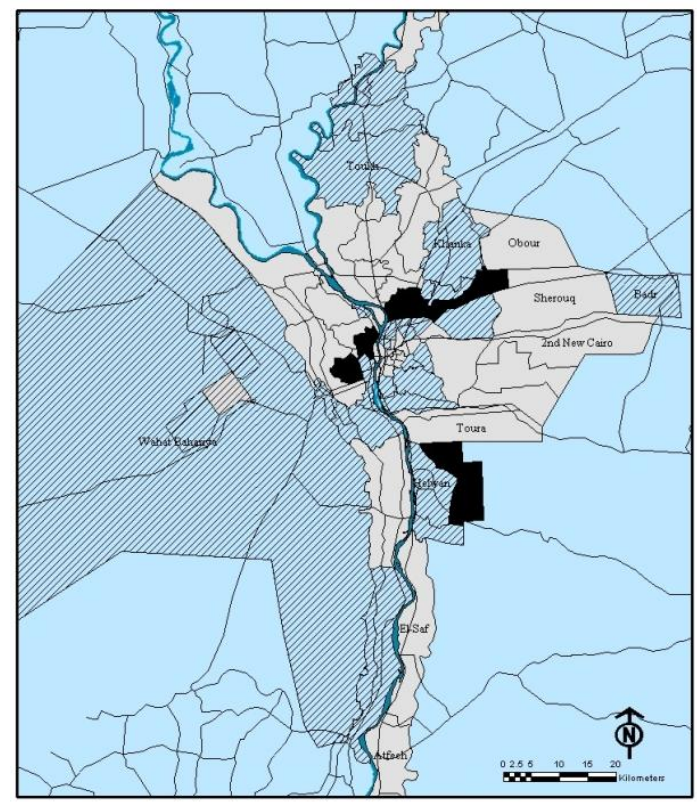

Fig. 8 Scores of employment discriminant analysis

\section{Identifying Deprived Districts}

The final step is using the most discriminating variables from both runs. The researchers used variables that have high canonical coefficients in Function 1 Education, and Function 1 Employment. The list of variables include illiterate persons, read and write without degree, illiteracy eradicated; primary-preparatory degree; secondary degree; business owner; self employed; employed for wage; employed without wage in family business; unemployed with working experience; and unemployed never worked before.

Eigen value for the first function, which explains almost 80 percent of the variation in deprivation index, is acceptable. However, its Wilks' Lambda is average but highly significant, which limits the use of the function for prediction. True, discriminant analysis is an explanatory analysis, but also an exploratory, which is useful in identifying pockets of poverty. Results show that 73.4 percent of original grouped cases correctly classified.

Function 1, Table 12, reflects education and employment, as the canonical coefficients suggest. It is the function that can predict where the illiterate without their own businesses live.

The structure matrix, Table 13, re-affirms the findings from Table 12. All starred values of the following variables: illiterate; read and write without degree; primary-preparatory degree; illiteracy eradicated; secondary degree; unemployed with working experience; and unemployed never worked before; are significant. 
Table 11, Summary of canonical discriminant

\begin{tabular}{ccccc}
\hline Eigen values & & & & \\
\hline Function & $\begin{array}{c}\text { Eigen } \\
\text { value }\end{array}$ & $\begin{array}{c}\% \text { of } \\
\text { Variance }\end{array}$ & $\begin{array}{c}\text { Cumulative } \\
\%\end{array}$ & $\begin{array}{c}\text { Canonical } \\
\text { Correlation }\end{array}$ \\
\hline 1 & $.890^{\mathrm{a}}$ & 79.7 & 79.7 & .686 \\
2 & $.226^{\mathrm{a}}$ & 20.3 & 100.0 & .430 \\
\hline
\end{tabular}

a. First 2 canonical discriminant functions were used in the analysis.

\begin{tabular}{ccccc}
\hline Wilks' Lambda & & & \\
\hline $\begin{array}{c}\text { Test of } \\
\text { Function(s) }\end{array}$ & $\begin{array}{c}\text { Wilks' } \\
\text { Lambda }\end{array}$ & Chi-square & df & Sig. \\
\hline 1 through 2 & .431 & 59.689 & 22 & .000 \\
2 & .815 & 14.481 & 10 & .152 \\
\hline
\end{tabular}

Table 12, Standardized canonical discriminant function coefficients

\begin{tabular}{lcc}
\hline & \multicolumn{2}{c}{ Function } \\
\cline { 2 - 3 } & 1 & 2 \\
\hline Illiterate & 1.040 & 1.015 \\
Read and Write without degree & 1.266 & $-2.458-$ \\
Illiteracy eradicated & $-.001-$ & 2.410 \\
Primary-Preparatory degree & $-1.869-$ & $-3.086-$ \\
Secondary degree & .748 & 2.841 \\
Business Owner & $-2.365-$ & $-2.046-$ \\
Self Employed & .253 & $-.272-$ \\
Employed for wage & $-.041-$ & $-.214-$ \\
Employed without wage in Family & 1.712 & 1.912 \\
business & \multicolumn{2}{c}{} \\
Unemployed with working experience & .481 & .310 \\
Unemployed never worked before & $-.318-$ & $-.135-$ \\
\hline
\end{tabular}

Table 13, Structure matrix

\begin{tabular}{lcc}
\hline & \multicolumn{2}{c}{ Function } \\
\cline { 2 - 3 } & 1 & 2 \\
\hline Illiterate & $.791^{*}$ & .139 \\
Read and Write without degree & $.788^{*}$ & .025 \\
Primary-Preparatory degree & $.753^{*}$ & $-.081-$ \\
Illiteracy eradicated & $.669^{*}$ & .382 \\
Secondary degree & $.651^{*}$ & $-.139-$ \\
Unemployed with working experience & $.425^{*}$ & $-.010-$ \\
Unemployed never worked before & $.359^{*}$ & $-.164-$ \\
Employed for wage & .347 & $-.358^{*}$ \\
Employed without wage in Family & .140 & $.333^{*}$ \\
business & & \\
Business Owner & .111 & $.329^{*}$ \\
Self Employed & .196 & $-.308^{*}$ \\
\hline
\end{tabular}

Again, the discriminant scores for function 1 were saved to the database, and used to map poverty pockets and gaps within GCR. Dark areas are the most deprived qism and markaz. They are rural pockets of Giza and Qalyubia, the residence of blue collar labor, such as Helwan, and informal areas such as the Kilo $2 \frac{1}{2}$ as depicted in Fig. 9. Most of GCR is around the medium category of deprivation - a finding that is in line with the national studies reviewed earlier. Area with light shade, such as the $6^{\text {th }}$ of October, Obour and Sherouq are all new settlements that are now the residents of the effluent Cairenes.

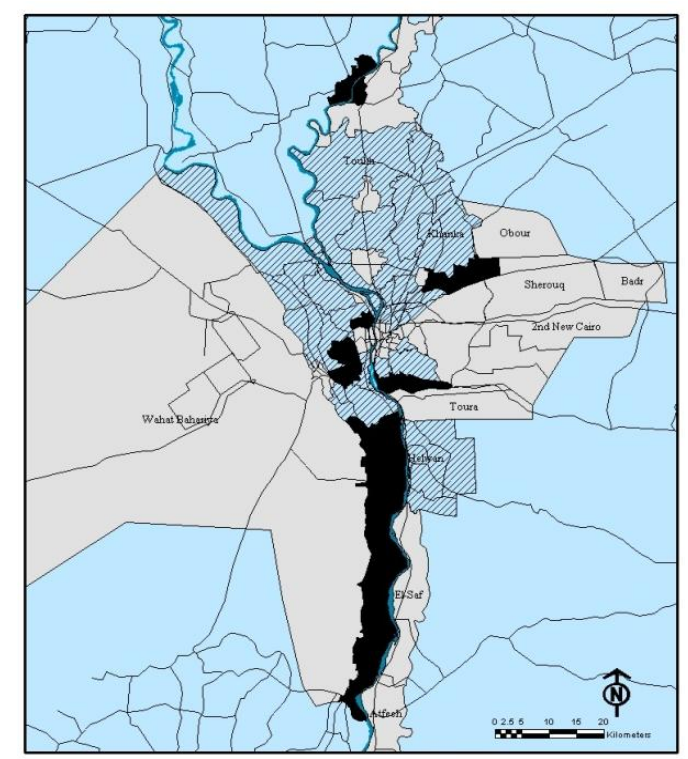

Fig. 9 Deprived locations in GCR

\section{CONCLUSION}

Poverty mapping has two primary uses. The first is spatial identification of the poor, on which this paper concentrates. Poverty mapping has in many instances served to target social, agricultural, emergency, environmental and anti-poverty programs. The second use is to create, as a byproduct, explanatory and dependent spatial variables for use in multivariate analysis in combination with recently developed tools that permit the spatial dimension to be incorporated in multivariate examination of poverty issues.

The paper shows that spatial determinants are important for understanding the distribution of assets that are fundamental for alleviating poverty; these include human resources such as health, employment, education and technology, and social capital such as the ability to cooperate and social networks.

GIS can be a proper tool for poverty targeting. It can map poverty and depravation areas according to various facets of poverty and deprivation. Based on the results of this exercise, poverty is not just lacking money to satisfy basic needs; rather empowering the poor and enabling them to access and control resources is one of the shortest, straight forward means to alleviate poverty. 
Education is important, but equally crucial is to provide them with means to use their skills. The exercise shows that graduate and post graduate education is not a positive asset, rather a burden and a hurdle to escape poverty. This does not mean to close both under- and post-graduate programs, and expand in technical education. It means the importance of Research and Development (R\&D), and depending on human resources, and science and technology to augment deficiencies in natural resources.

\section{REFERENCES AND NOTES}

[1] Mistiaen, Johan A., Özler, Berk; Razafimanantena, Tiaray; and Razafindravonoma, Jean, August 2002, "Putting Welfare on the Map in Madagascar," Africa Region Working Paper Series No. 34, The World Bank: Washington DC, USA http://www.worldbank.org/afr/wps/index.htm. accessed 15 May 2010; 18:48

[2] Baharaoglu and Kessides, 2002, "Urban Poverty" in World Bank, 2002, A Sourcebook for Poverty Reduction Strategies, Chapter 16.

[3] Coudel, Hentschel, and Wodon, in World Bank, 2002.

[4] Moser, C., M. Gatehouse, and H. Garcia. 1996a. "Urban Poverty Research Sourcebook Module I: Sub-City Level Household Survey." Urban Management Program Working Paper Series 5. UNDP/UNCHS

[5] Chen and Ravallion, 2000, "How did the World ill's Poorest Fare in the 1990s," Policy Research Working Paper, World Bank, Washington, DC.

[6] De Haan, Arjan. 1999. "Livelihoods and Poverty: The Role of Migration. A Critical
Review of the Migration Literature." Journal of Development Studies London: Frank Cass

[7] Falkingham, J. and C. Namazie, 2002, Measuring Health and Poverty: A review of approaches to identifying the poor, London, DFID Health Systems Resource Center, and Montgomery, M.R., M.

[8] Baharaoglu and Kessides, 2002, "Urban Poverty" in World Bank, 2002, A Sourcebook for Poverty Reduction Strategies, Chapter 16.

[9] Moser, C., M. Gatehouse, and H. Garcia. 1999b. "Urban Poverty Research Sourcebook Module II: Sub-City Level Household Survey." Urban Management Program Working Paper Series 5. UNDP/UNCHS (Habitat)/World Bank, Washington, D.C.

[10] Afifi, A. and V. Clark, 1984, Computer Aided Multivariate Analysis, Van Nostrand Reinhold Company, New York, New York.

[11] Clark, David, 1982, Urban Geography, The John Hopkins University, Baltimore, Maryland.

[12] Al-Shawarby, Sherine, Arab Republic of Egypt: Poverty Assessment Update, 2006, Ministry of Economic Development and World Bank Cairo, Egypt.

[13] Afifi, A. and V. Clark, 1984 (Ref. Op. Cited)

[14] Ibid.

[15] It is known in some texts as U-statistics. It is a ratio of within-groups sum of squares to the total sum of squares. A Lambda of one occurs when all observed group means are equal. Wilks' Lambda is the criterion used for selecting the variables that entered the analysis. Smaller Wilks Lambda means stronger relationship. 